\section{Cerebrovascular ischemic event - what about the coronaries}

To the Editor,

We are in agreement with Poledník et al. (1) that assessment for myocardial ischemia is needed in patients with acute ischemic stroke (AIS) or transient ischemic attack. This is also supported by a number of studies, including the meta-analysis by Touzé et al. (2). This should not be surprising given the shared risk factors as mentioned in the review. These patients undoubtedly have a significant risk for coronary events as the review suggested that significant stenosis of at least one coronary artery can be found in $31 \%$ of these patients. Many of these may be silent up to that point, and detection and adequate treatment of such silent disease may improve the long-term outcome and survival of these patients.

Intra- and extra-cranial cerebral vascular imaging is becoming part of the routine care of patients with AIS. These imaging findings define the severity and extent of atherosclerotic disease and can predict the presence of concurrent significant coronary artery disease (CAD), especially when combined with clinical characteristics and other vascular risk factors (3). Transthoracic echocardiography (TTE) at rest is routinely done for all the patients with stroke and sometimes reveals wall motion abnormalities not known previously, in keeping with previously unrecognized ischemic heart disease. This is now the standard of care for all patients with AIS in our hospital.

Testing of all the patients may not be necessary, and patient selection needs to be refined. The combination of patient clinical characteristics, TTE findings, and cerebral vascular imaging added to the subtype of AIS on the basis of a Trial of Org 10172 in acute stroke treatment classification might be all that is needed to identify patients who would benefit from screening for CAD (4).

We have found that myocardial perfusion scintigraphy (MPS) is often ideal for assessment of patients in such a situation. Compared with coronary angiography, it is a painless investigation as it is noninvasive (5). It provides a functional assessment, and therefore, shows if further treatment or intervention is urgently required. It also correlates well with the prognosis (5), regardless of findings on angiography, even if discrepant. Fractional flow reserve assessment by computed tomography (developed more recently) is currently only available in some centers - not all - and requires specialized software and sub-specialist radiologists with appropriate training.

Stress echocardiography also can provide a functional assessment but is also potentially very operator dependent. In addition, exercise may be unsuitable for some patients following stroke owing to residual neurological deficits. The alternative, using dobutamine, is often unsuitable also as a sympathomimetic may be contraindicated.

In terms of medical therapy for patients with AIS, the major elements are anti-platelet and high intensity anti-cholesterol therapy along with optimizing the control of other vascular risk factors, including hypertension and diabetes. Randomized controlled trials are needed to clarify if invasive coronary interventions for concurrent significant CAD in properly selected patients will impact the future incidence of major adverse cardiac events, compared with the currently provided medical therapy for their vascular cerebral complication.

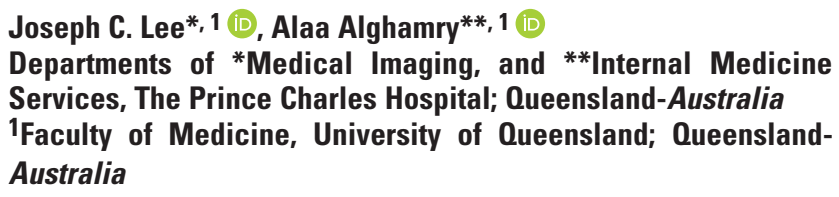

\section{References}

1. Poledník I, Sulzenko J, Widimsky P. Risk of a coronary event in patients after ischemic stroke or transient ischemic attack. Anatol J Cardiol 2021; 25: 152-5. [Crossref]

2. Touzé $\mathrm{E}$, Varenne $\mathrm{O}$, Calvet $\mathrm{D}$, Mas $\mathrm{JL}$. Coronary risk stratification in patients with ischemic stroke or transient ischemic stroke attack. Int J Stroke 2007; 2: 177-83. [Crossref]

3. Yoo J, Yang JH, Choi BW, Kim YD, Nam HS, Choi HY, et al. The frequency and risk of preclinical coronary artery disease detected using multichannel cardiac computed tomography in patients with ischemic stroke. Cerebrovasc Dis 2012; 33: 286-94. [Crossref]

4. Kolominsky-Rabas PL, Weber M, Gefeller 0, Neundoerfer B, Heuschmann PU. Epidemiology of ischemic stroke subtypes according to TOAST criteria: incidence, recurrence, and long-term survival in ischemic stroke subtypes: a population-based study. Stroke 2001; 32: 2735-40. [Crossref]

5. Lee JC, West MJ, Khafagi FA. Myocardial perfusion scans. Aust Fam Physician 2013; 42: 564-7.

Address for Correspondence: Joseph C. Lee, MD,

Department of Medical Imaging, The Prince Charles Hospital; Queensland-Australia Phone: +61-7-3139 4000

E-mail: Joseph.Lee@health.qld.gov.au

CCopyright 2021 by Turkish Society of Cardiology -

Available online at www.anatoljcardiol.com

DOI:10.5152/AnatolJCardiol.2021.245

\section{Author`s Reply}

To the Editor,

We would like to thank the authors for their valuable comments on our review (1). We agree that all patients with acute ischemic stroke should undergo transthoracic echocardiography; not only for revealing wall motion abnormalities, but also for possible detection of patent foramen ovale as a risk factor in patients with cryptogenic stroke (2).

Non-invasive techniques are preferred when screening for silent coronary artery disease in patients with stroke. Besides myocardial 
perfusion scintigraphy, coronary computed tomography angiography seems to be a good option as well. It is very accurate and has a high negative predictive value (3). Selecting high-risk patients who should undergo these examinations still needs to be defined.

\section{References}

1. Poledník I, Sulzenko J, Widimsky P. Risk of a coronary event in patients after ischemic stroke or transient ischemic attack. Anatol J Cardiol 2021; 25: 152-5. [Crossref]

2. Mojadidi MK, Zaman MO, Elgendy IY, Mahmoud AN, Patel NK, Agarwal N, et al. Cryptogenic Stroke and Patent Foramen Ovale. J Am Coll Cardiol 2018; 71: 1035-43. [Crossref]
3. Chang SM, Bhatti S, Nabi F. Coronary computed tomography angiography. Curr Opin Cardiol 2011; 26: 392-402. [Crossref]

Ivan Poledník (D), Jakub Sulzenko (D), Petr Widimsky (D) Department of Cardiology, Third Faculty of Medicine, Charles University and University Hospital Kralovske Vinohrady; Prague-Czech Republic

Address for Correspondence: Ivan Poledník, MD,

Department of Cardiology, Third Faculty of Medicine, Charles University and University Hospital Kralovske Vinohrady; Prague-Czech Republic Phone: 00420606647144

E-mail: ivan.polednik@fnkv.cz (C) Copyright 2021 by Turkish Society of Cardiology - Available online at www.anatoljcardiol.com 